Agricultural and Environmental Chemistry

Subscriber access provided by Nottingham Trent University

\title{
Enhancement of tomato plant growth and productivity in organic farming by agri-nanotechnology using nanobubble oxygation
}

Yuncheng Wu, Tao Lyu, Bin Yue, Elisa Tonoli, Elisabetta A.M. Verderio, Yan Ma, and Gang Pan

J. Agric. Food Chem., Just Accepted Manuscript • DOI: 10.1021/acs.jafc.9b04117 • Publication Date (Web): 05 Sep 2019

Downloaded from pubs.acs.org on September 5, 2019

\section{Just Accepted}

"Just Accepted" manuscripts have been peer-reviewed and accepted for publication. They are posted online prior to technical editing, formatting for publication and author proofing. The American Chemical Society provides "Just Accepted" as a service to the research community to expedite the dissemination of scientific material as soon as possible after acceptance. "Just Accepted" manuscripts appear in full in PDF format accompanied by an HTML abstract. "Just Accepted" manuscripts have been fully peer reviewed, but should not be considered the official version of record. They are citable by the Digital Object Identifier (DOI®). "Just Accepted" is an optional service offered to authors. Therefore, the "Just Accepted" Web site may not include all articles that will be published in the journal. After a manuscript is technically edited and formatted, it will be removed from the "Just Accepted" Web site and published as an ASAP article. Note that technical editing may introduce minor changes to the manuscript text and/or graphics which could affect content, and all legal disclaimers and ethical guidelines that apply to the journal pertain. ACS cannot be held responsible for errors or consequences arising from the use of information contained in these "Just Accepted" manuscripts. 


\section{Enhancement of tomato plant growth and productivity in}

2 organic farming by agri-nanotechnology using nanobubble

3 oxygation

4

Yuncheng $\mathbf{W u}^{1, a, b, c, d}$, Tao Lyu ${ }^{1, c, d}$, Bin Yue ${ }^{c, d, e}$, Elisa Tonolif, Elisabetta A.M.

\section{Verderiof, Yan Ma*a, Gang Pan*c,d}

alnstitute of Agricultural Resources and Environment, Jiangsu Academy of Agricultural Sciences, Nanjing 210014, China

${ }^{b}$ Nanjing Institute of Environmental Sciences, China Ministry of Environmental Protection, Nanjing 210000, China

'School of Animal, Rural, and Environmental Sciences, Nottingham Trent University, Brackenhurst Campus, Nottinghamshire NG25 OQF, United Kingdom

${ }^{d}$ Centre of Integrated Water-Energy-Food studies (iWEF), Nottingham Trent University, Nottinghamshire NG25 OQF, United Kingdom

${ }^{e}$ College of Geography and Environmental Engineering, Lanzhou City University, Lanzhou, Gansu 730070, China

fSchool of Science and Technology, Nottingham Trent University, Clifton Campus NG11 8NS, UK

*Corresponding authors: myjaas@sina.com (Y. Ma); gang.pan@ntu.ac.uk (G. Pan)

${ }^{1}$ These authors are co-first authors and contribute equally to this work. 


\section{Abstract}

Development of technology to improve the mineralization of organic fertilizer and to enhance crop production is essential to achieve the transition from traditional farming to eco-friendly organic farming. Nanobubble oxygation (NB) was employed to compare with traditional pump aerated oxygation (AW) and a control group through both soil incubation and soil column experiments. Plant-available N and P contents in the NB treatment group were higher than that in the AW and control groups. Enzymatic activities including $\beta-1,4-N$-acetylglucosaminidase, phosphatase, $\alpha-1,4$-glucosidase, $\beta-1,4-x y l o s i d a s e$, peroxidase, and phenol oxidase were significantly higher in both oxygation groups compared with the control. The soil microbial biomass, activity, and diversity were also significantly improved due to the oxygation treatment. Additionally, the microbial metabolic functions were shifted in both oxygation treatments compared with the control group. The final tomato yield increase from the NB treatment group was $23 \%$, and that from the AW treatment $17 \%$, compared with the control.

Keywords: Agricultural sustainability; crop intensification; organic farming; precision farming; oxygen nanobubble 


\section{TOC Art}

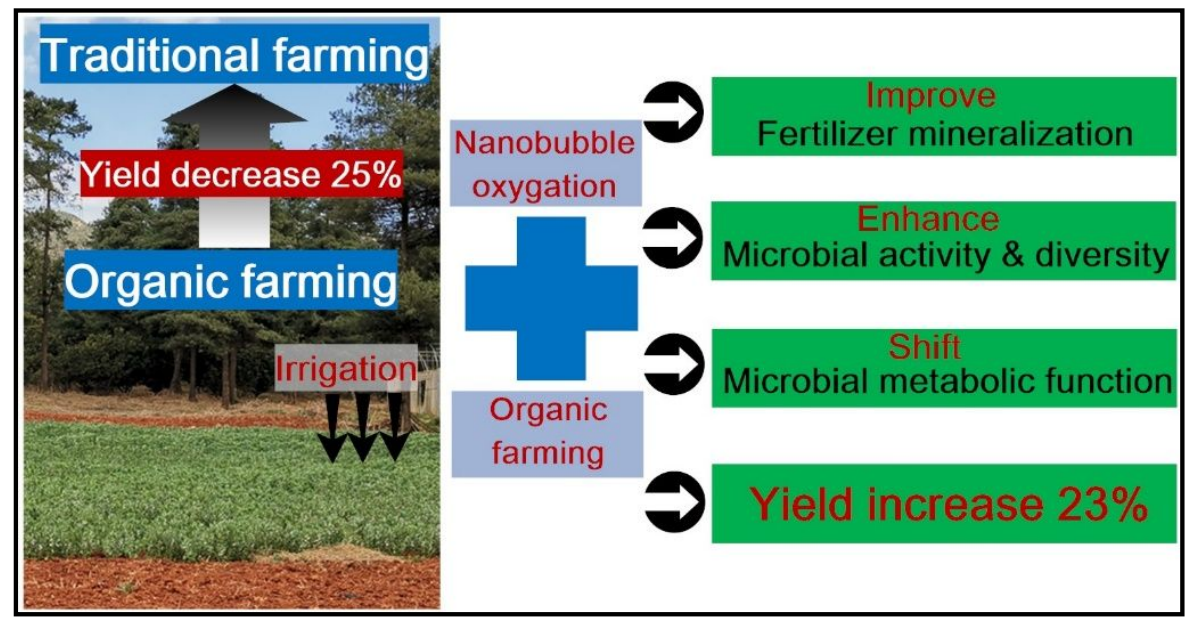




\section{Introduction}

Currently, an estimated 124 million people in 51 countries are facing crises from food insecurity and shortage based on the 2018 report by UN's World Food Programme (WFP). One of the greatest challenges is how to increase 50 percent of food production to ensure that the growing global population - predicted to be around 10 billion by 2050 - has enough food to meet their nutritional needs. Many techniques and approaches have been developed in order to improve crop growth and yield, a simple approach being to increase the application of chemical fertilizer in the traditional farm. ${ }^{1}$ However, increased fertilizer usage on farmland can cause groundwater pollution, ${ }^{2}$ surface water eutrophication, ${ }^{3}$ and nutrient loss ${ }^{4}$ though runoff or leaching. To avoid the adverse impact on both environment and ecosystem, ${ }^{5}$ it is essential to develop an eco-friendly approach for the enhancement of agricultural crop production.

Organic farming is an ideal environmentally-friendly agricultural system, which relies on organic fertilizers derived from livestock manure, crop residues or human excreta. ${ }^{6}$ Organic farming also strives for sustainability by promoting natural pest control and minimising environment pollution from synthetic pesticides and antibiotics. ${ }^{7}$ However, in organic farming, the applied nutrients from the organic fertilizer can only be utilized by crops after decomposition and mineralization of organic matter and release of plant-available nutrients, such as nitrogen and phosphorous. It has been reported that only $35 \%, 39 \%$, and $53 \%$ of the plant-available nitrogen can be released from cow, pig and chicken manures on farmland over 6 months, respectively. ${ }^{8}$ As a result, crop production in organic farming has been demonstrated to be up to $25 \%$ lower than that in conventional agriculture using chemical 
fertilizer. ${ }^{9}$ This slow release of mineral nutrients from organic fertilizer has become the major yield-limiting factor, ${ }^{10}$ which indicates that further research could focus on the acceleration of the mineralization of organic fertilizer in organic farming.

The mineralization is driven by microbial biodegradation processes, where oxygen is crucial in order to improve the bio-decomposition rate. The soil oxygen content in traditional farmland originates mainly from air diffusion, which is always limited, especially in the deep soil layer. Thus, an appropriate method to deliver sufficient oxygen into the soil is crucial to improve microbial activity. The application of aerated water to the farmland through a drip irrigation system has been used to deliver oxygen to the crop root zone. ${ }^{11}$ Previous studies demonstrated that these approaches could not only enhance crop yields, but could also improve the nutrition quality of fruit. ${ }^{12}$ To improve the soil oxygenation efficiency, the aeration pump was upgraded from common air pumps, fine bubble diffusers and to venturi injectors. ${ }^{13}$ The main aim of the development of this technique was to deliver smaller-sized air bubbles into irrigation water and to improve oxygen dissolution efficiency. Recently, nanobubble technology (NBs; defined as bubbles with diameters less than $1000 \mathrm{~nm},{ }^{14,15}$ has attracted increasing attention due to characteristics of high gas solubility and long lifetime of oxygen in the liquid. ${ }^{3,16}$ The use of a mixture of micro- and nano- bubbles has been used for the oxygation in drip irrigation systems for water saving and for increasing vegetable yields. ${ }^{17}$ Air, oxygen and nitrogen saturated nanobubble waters, used for irrigation, have been demonstrated to improve the yield of such plants as lettuce, and seed germination and biomass growth. ${ }^{18,19}$ However, the effect of the nanobubble technology on the mineralization of organic fertilizer still need to be demonstrated. 

plant physiology, crop yield, quality, and water use efficiency. Soil oxygation can directly

improve the plant root growth and nutrient uptake by providing required oxygen for root respiration and energy generation. ${ }^{20}$ However, evaluating the effect of oxygation on soil properties is also important in order to reveal the mechanisms for crop yield enhancement. It has been proven that soil microbial structure, activity and metabolic functions in the soil could be altered, associated with the change of soil oxygen content. ${ }^{21}$ Moreover, enzyme activity in soil is important as it directly influences biochemical processing of soil nutrients. ${ }^{22}$ Therefore, studying the metabolic functioning of the microbial community, and soil enzyme activity, coupled with the mineralization of organic fertilizer after the oxygation treatment, can help us better understand the mechanisms of altered crop growth.

To evaluate the effect of the proposed nanobubble oxygation method on organic fertilizer mineralization and crop growth, the tomato plant and cow manure compost were selected as the model crop and target organic fertilizer, respectively. Firstly, a soil incubation experiment was conducted to 1 ) investigate the effect on organic fertilizer mineralization by monitoring the plant available nitrogen $\left(\mathrm{NH}_{4}{ }^{+}, \mathrm{NO}_{3}{ }^{-}\right)$and phosphorus $\left.\left(\mathrm{PO}_{4}{ }^{3-}\right) ; 2\right)$ evaluate the influence on soil enzymes activities related to $\mathrm{C}-, \mathrm{N}-$, and $\mathrm{P}$-cycling; 3 ) detect the response of the metabolic functioning of the soil microbial community. Secondly, a soil column experiment was set up to 4) study the hypothesized positive effect of nanobubble oxygation on tomato growth and yield. From the results, this study aimed to demonstrate a promising agrinanotechnology, nanobubble oxygation, for the improvement of crop yields in organic farming. 


\section{Materials and methods}

102

103

104

105

106

107

108

109

110

\subsection{Aerated water and nanobubble solution preparation}

The oxygen nanobubble aerated water was generated by a nanobubble generator (KTM, Nikuni Co., Ltd., Kanagawa, Japan). Briefly, the generator was operated by recirculation of a fixed volume of $20 \mathrm{~L}$ deionized water at a flow rate of $1000 \mathrm{~L} / \mathrm{h}$. The superficial liquid velocity in the column was $0.035 \mathrm{~m} / \mathrm{s}$, and the residence time in the system was approximately 2.1 min. Pure oxygen $(>99 \%)$ and air $(v / v=1: 1)$ were injected into the system under the gas flow of $0.45 \mathrm{~L} / \mathrm{m}$. The system was run for $5 \mathrm{~min}$ before use, and the dissolved oxygen (DO) of the irrigation water was approximately $15 \mathrm{mg} / \mathrm{L}$ measured by a DO meter (HQ4Od, HACH, USA). In order to set a comparable irrigation water as the traditional oxygation treatment, pure oxygen and air ( $/ \mathrm{v}=1: 1)$ was used to aerate $20 \mathrm{~L}$ deionized water under the gas flow of $0.45 \mathrm{~L} / \mathrm{m}$. The aeration was stopped after approximate 5 mins when the DO of aerated water reached 15 $\mathrm{mg} / \mathrm{L}$ under the directly measurement by a DO meter (HQ40d, HACH, USA). Thus, the gas volume used for nanobubble solution and aerated water solution were both around $2.25 \mathrm{~L}$.

\subsection{Soil incubation experiment}

A laboratory-scale soil incubation experiment (Fig. 1a) was performed in order to investigate the combined effects of oxygation and organic fertilizer application in the soil. Two treatment groups were designed as 1) cow manure applied soil, irrigated by nanobubble aerated deionized water (NB) and 2) cow manure applied soil, irrigated by traditional aeration deionized water (AW). A control group was set as 3) cow manure applied soil irrigated by original deionized water (Control). Before the incubation experiment, the cow manure compost was mixed and passed through a $2 \mathrm{~mm}$ sieve. The sieved cow manure compost was 
mixed with $600 \mathrm{~g}$ of the topsoil at a rate of $1.5 \%$ then placed in $1 \mathrm{~L}$ transparent plastic jars.

The soil was compacted to give a bulk density of $1.3 \mathrm{~g} \mathrm{~cm}^{-3}$. The jars were covered with loose

lids to allow air circulation but to minimize water evaporation. There were twelve replicates

with constantly dark environment at $25^{\circ} \mathrm{C}$. During the incubation period, all soil jars were

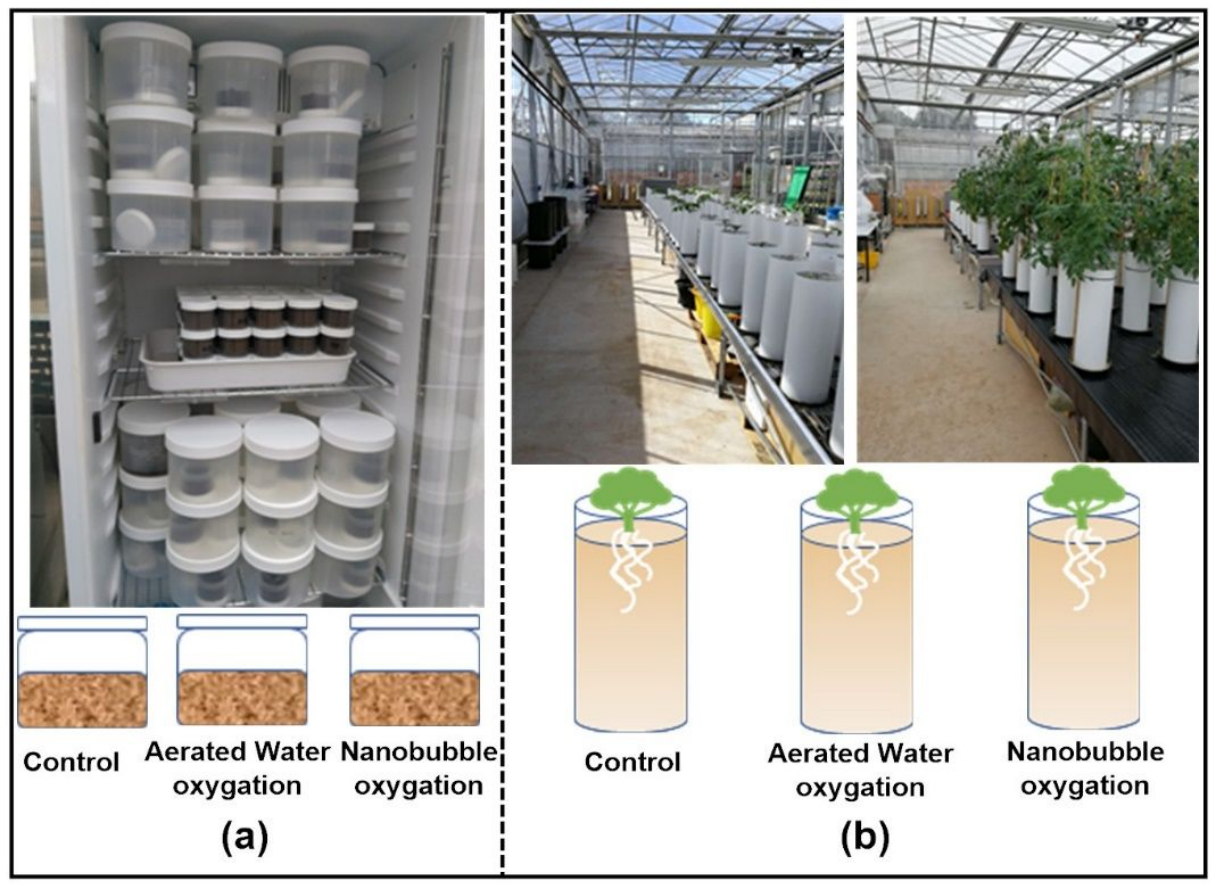

Fig. 1. Schematics and photos of the lab-scale soil incubation (a) and soil column (b) experiments.

\subsection{Soil column experiment for tomato growth}

To evaluate the effect of combined oxygation and organic fertilizer application on

tomato biomass growth and yield, a greenhouse soil column experiment was performed (Fig. 
137 at Brackenhurst campus, Nottingham Trent University, UK. The three experimental groups 138 were designed as follows: 1) the control group (Control, original deionized water + cow 139 manure compost), 2) the aerated water oxygation treatment group (AW, normal bubble 140 aerated water + cow manure compost), and 3) the nanobubble oxygation treatment group 141 (NB, oxygen nanobubble aerated water + cow manure compost). In each group, 12 replicated, 142 planted, soil columns were prepared. Each soil column was $25 \mathrm{~cm}$ high with a diameter of 15 $143 \mathrm{~cm}$. Topsoil (0-20 cm, 29\% sand, $42 \%$ silt, and $29 \%$ clay), collected from Embleys Farm in the 144 UK, was air dried and sieved by $2 \mathrm{~mm}$ mesh. Then, $5 \mathrm{~kg}$ of topsoil was mixed with $75 \mathrm{~g}$ of cow 145 manure compost before filling the columns. The same size of tomato seedlings at the 3 to 4 146 leaf stage were then transplanted into each pot. The plants were watered every day during 147 the experiment to maintain $65 \%$ field water-holding capacity.

\subsection{Sampling and analysis}

\subsubsection{Nanobubble analysis}

The sizes $(<1000 \mathrm{~nm})$ and distributions of nanoscale bubbles in the traditional aerated and nanobubble aerated deionized waters were determined by nanoparticle tracking analysis by ZetaView PMX 120 (Particle Metrix, Meerbusch, Germany) and its corresponding software ZetaView 8.04.02. The samples were collected after 5 mins of preparation and the analyses carried out at room temperature. Each sample was analysed with a flow cell sensitivity of $70 \%$ across two cycles of 11 positions/cycle.

\subsubsection{Sampling strategies}


158

159

during the experiment. The soil in three replicated jars from each treatment group were collected after homogenization by mixing with a glass rod. After sifting the soil samples through a 2-mm sieve, the soil was air-dried prior to the determination of plant-available nutrients, $\mathrm{N}$ and $\mathrm{P}$. At day 28 , each soil sample was divided to three parts for nutrient analysis (part I) and the determination of dissolved organic carbon (DOC) and microbial biomass carbon (part II). The remainder of the soil samples (part III) were used to analyse the soil enzyme activity and microbial community metabolic functions. For the soil column experiment, the diameter of stem, and the height of tomato plants was recorded at 15, 30,45 days. Tomato fruit from each treatment was harvested and weighed at day 70 .

\subsubsection{Soil chemical properties}

The plant-available nitrogen $\left(\mathrm{NH}_{4}{ }^{+}-\mathrm{N}\right.$, and $\left.\mathrm{NO}_{3}{ }^{-}-\mathrm{N}\right)$ in soil samples was extracted by $2 \mathrm{M}$ $\mathrm{KCl}$ solution according to the method described by Tu et al., (2006). ${ }^{23}$ Plant-available phosphorus $\left(\mathrm{PO}_{4}{ }^{3-}-\mathrm{P}\right)$ was extracted with $0.5 \mathrm{M} \mathrm{NaHCO}_{3}$ following a previously-reported method. ${ }^{24}$ The concentrations of $\mathrm{NH}_{4}{ }^{+}-\mathrm{N}, \mathrm{NO}_{3}{ }^{-}-\mathrm{N}$, and $\mathrm{PO}^{3-}-\mathrm{P}$ in the extracts were determined by analysis on an AQ400 nutrients auto-analyzer (Seal Analytical, Southampton, UK). The chloroform fumigation-extraction method was used to determine the microbial biomass carbon (MBC). The dissolved organic carbon (DOC) content of the extract was measured by a Shimadzu TOC-V Total Organic Carbon Analyser (Shimadzu Corp., Kyoto, Japan).

\subsubsection{Soil enzyme activities}

In the soil cultivation experiment, the hydrolytic enzymes, peroxidase, phenol oxidase, $\alpha-1,4$-glucosidase, and $\beta-1,4$-xylosidase were selected as indicators for $C$ acquisition. ${ }^{25}$ The 
179

180

terminal reaction in chitin degradation can be catalyzed by $\beta-1,4-\mathrm{N}$-acetyl-glucosaminidase, thus it was evaluated as one of the $\mathrm{N}$-targeting hydrolytic enzymes. ${ }^{26}$ Phosphatase is the enzyme responsible for releasing labile inorganic $\mathrm{P}$ for microbes and plants. ${ }^{27}$ The activities of all extracellular enzymes, except for phenol oxidase and peroxidase, were measured by using the MUB-linked model substrate method described by Zhao et al., (2016). ${ }^{28}$ The phenol oxidase and peroxidase activities were measured spectrophotometrically by using L-3,4dihydroxy-phenylalanine as the substrate in a clear 96-well microplate.

\subsubsection{Microbial metabolic functions}

In the soil cultivation experiment, community-level physiological profiling (CLPP) of the soil samples were assessed by using Biolog EcoPlate ${ }^{\mathrm{TM}}$ (Biolog Inc., California, USA). ${ }^{29}$ A $1000-$ fold serial dilution of the rhizosphere soil suspension was made and $150 \mu$ l aliquots were added to each well in the microplates. Soil particles were not removed, nor allowed to settle, during any step in the extraction or inoculation. The plates were then packed into polyethylene bags to reduce evaporation and were incubated in the dark at $25^{\circ} \mathrm{C}$. Absorbance at $590 \mathrm{~nm}$ was measured on an automated microplate reader (Tecan Group Ltd. Austria) after 24, 48, 72, 96, 120, 144 and 168 of incubation hours. Each well absorbance value was corrected by subtraction of the optical density of a control well. The CLPP data was analysed, based on the previous studies, ${ }^{30,31}$ to calculate the average well colour development (AWCD) and Shannon diversity indexes.

\subsection{Statistical analyses}

The data were assessed with one-way ANOVA. Duncan's multiple-range test was applied 
200

201

202

203

204

205

206

207

208

209

210

211

212

213

214

215

216

when one-way ANOVA revealed significant differences $(p<0.05)$. All data were tested for a normal distribution and variance homogeneity using Levene's test. The statistical analyses were performed with SPSS ver. 13.0 statistical software (SPSS, Chicago, IL, USA). In addition, a Principal Components Analysis (PCA) was performed on correlation matrix of CLPP results using Origin Pro 2016 software (OriginLab Corp., Massachusetts, USA). For PCA analysis, data were standardized by autoscaling method prior to analysis to ensure that each variable had the same influence in the analysis.

\section{Results}

\subsection{Nanobubbles distribution in oxygenated waters}

The aerated waters prepared for irrigation were analysed in the nanoparticle-tracking analysis instrument to detect the size and distribution of the nanobubbles (Fig. 2). The concentration of nanobubbles $(<1000 \mathrm{~nm})$ was $4.1 \times 10^{7}$ particles $/ \mathrm{mL}$ in the aerated irrigation water prepared by the traditional pump (Fig. 2a), however, a one-magnitude higher nanobubble concentration $\left(7.5 \times 10^{8}\right.$ particles $\left./ \mathrm{mL}\right)$ was observed in the nanobubble-aerated water after 5 mins operation (Fig. 2b), with $87 \%$ below $200 \mathrm{~nm}$ in diameter. It should be noted that the deionized water before any aeration treatment contained undetectable concentrations of nanobubble $\left(<10^{4}\right.$ particles $/ \mathrm{mL}$; data is not shown). 

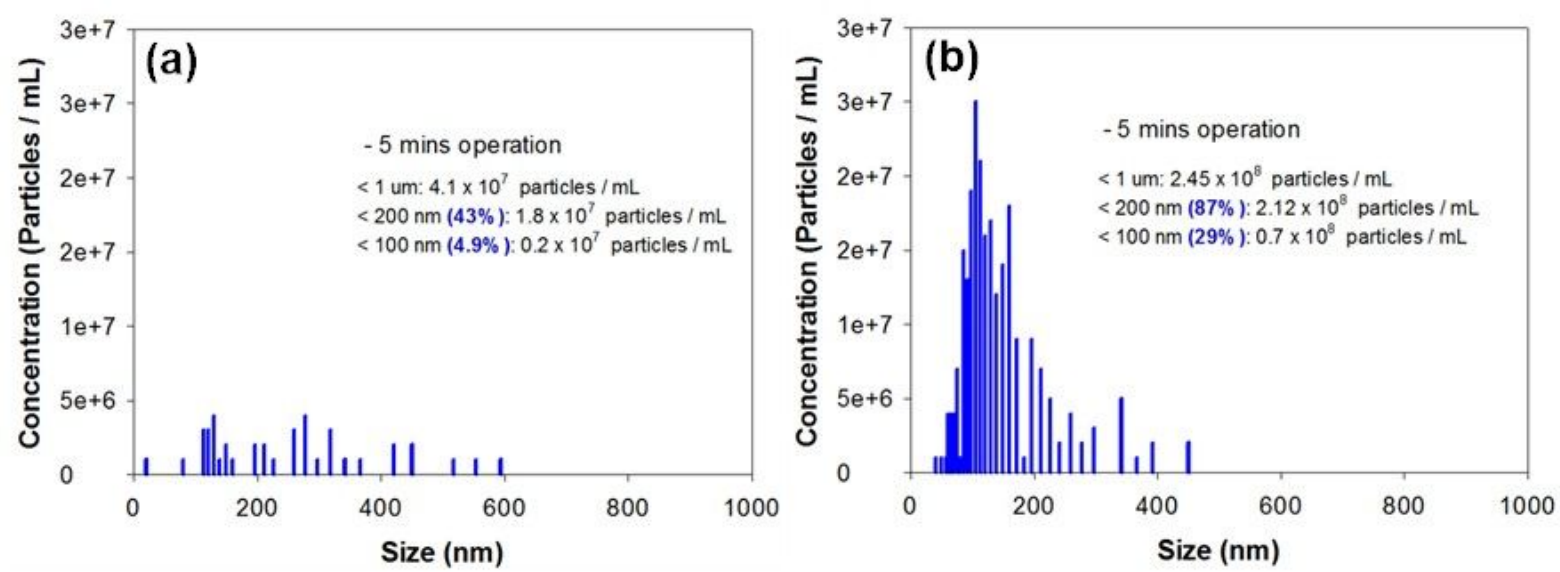

Fig. 2. Nano-scale bubbles size and distribution in traditional aerated (a) and nanobubble aerated (b)

solutions, measured by NTA.

\subsection{Plant-available nutrients and organics}

The total plant-available $\mathrm{N}\left(\mathrm{NH}_{4}{ }^{+}+\mathrm{NO}_{3}{ }^{-}\right)$content generally increased from around 38

$\mathrm{mg} / \mathrm{kg}$ to 50,56 , and $66 \mathrm{mg} / \mathrm{kg}$ at day 28 , in the control, AW treatment and NB treatment

groups, respectively (Fig. 3a). Compared with the control group, enhancements of $12 \%$ and $32 \%$

total available $\mathrm{N}$ were observed in the AW and NB treatment groups, respectively. It can be available $\mathrm{P}$ in the soil was detected in all groups throughout the experiment, where the soil from NB treatment group contained significantly higher $P$ concentrations $(5.9 \mathrm{mg} / \mathrm{kg})$, 
and $26 \%$, respectively, compared to the control treatment.
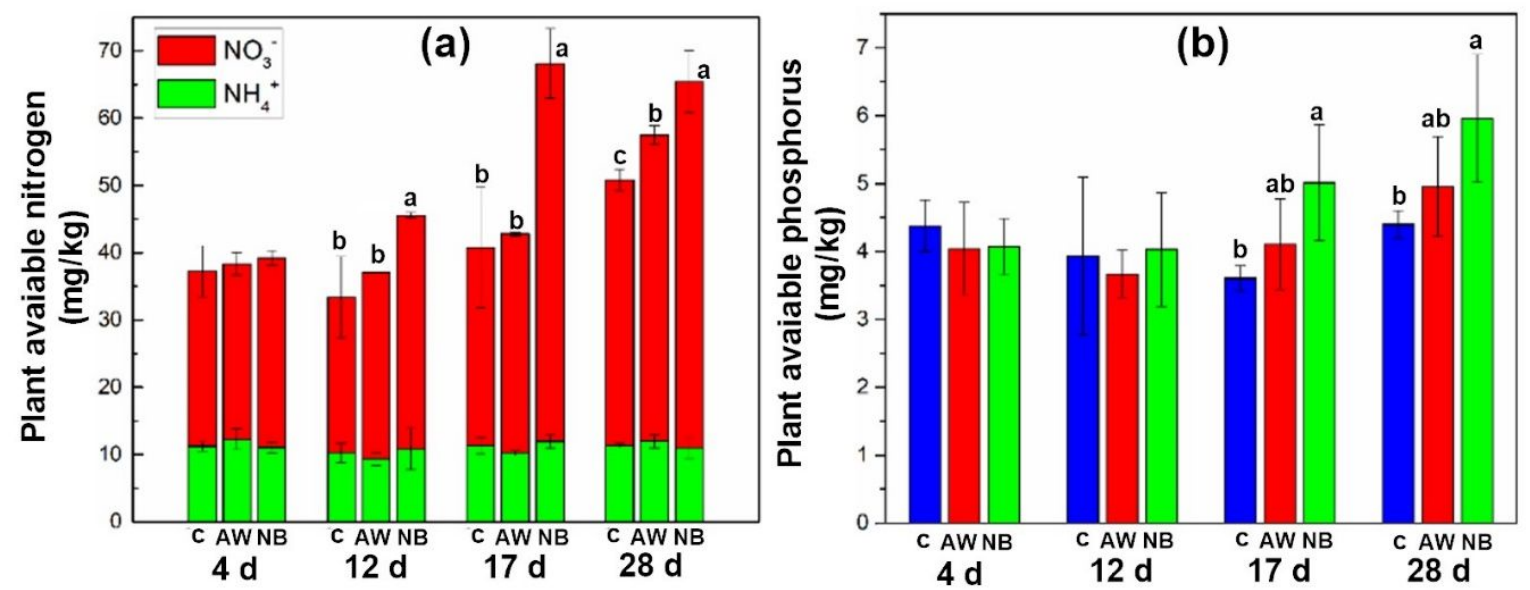

100

(c)
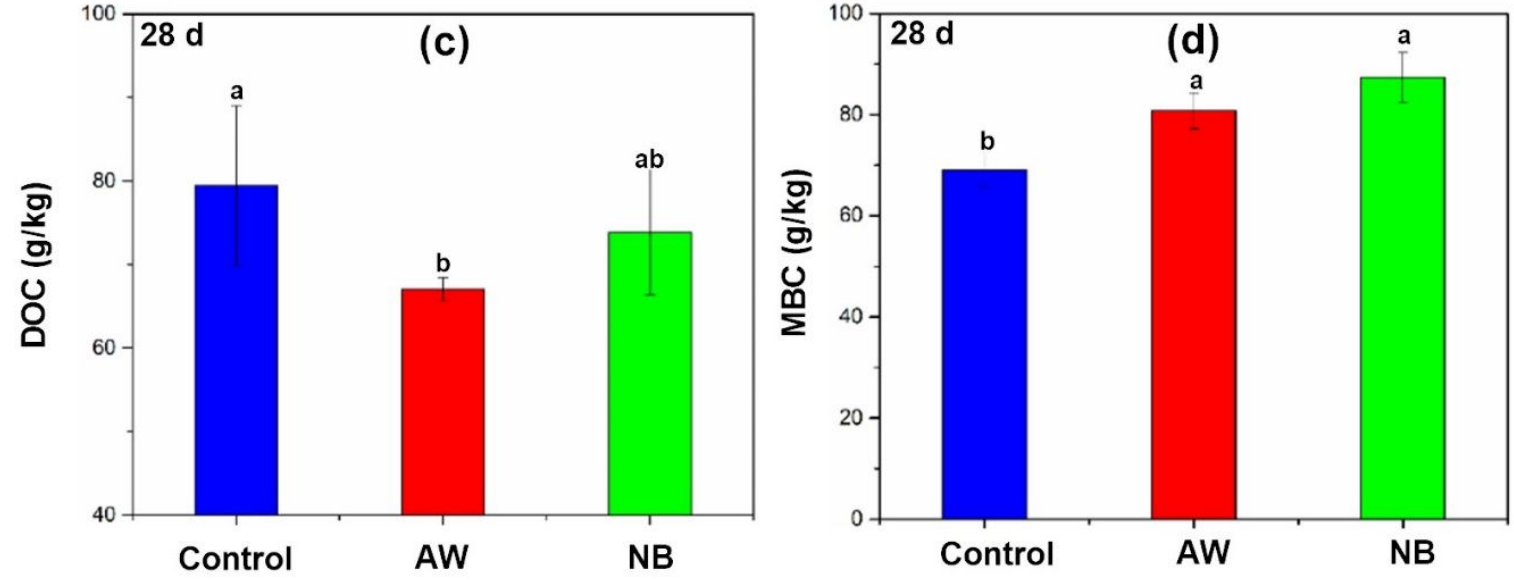

Fig.3. Effect of oxygation on plant-available nutrients, i.e. (a) nitrogen and (b) phosphorus, (c) dissolved

organic carbon (DOC), and (d) microbial biomass carbon (MBC) in soil incubation experiments. Control:

irrigation with original water, AW: irrigation with traditional pump-aerated water, NB: irrigation with

nanobubble-aerated water. Different letters above the bars in each figure indicate significant

241 difference $(P<0.05)$ between three groups in the same sampling day.

\subsection{Soil enzyme activities}

After the soil incubation experiment, soil enzyme activities were analysed to understand the mechanisms of nutrient mineralization. All six enzymes exhibited higher activities in the 
soil samples from the oxygation (AW or NB) treatment groups (Fig. 4). The activities of $\mathrm{N}$ mineralization related enzyme, $\beta-1,4-\mathrm{N}$-acetyl-glucosaminidase (Fig. 4a), and P-mineralization related enzyme, Phosphatase (Fig. 4b), were significantly higher in the oxygenated groups

in the enzyme activity, though for both enzyme activity was higher than for the control group.

For the C-cycling related enzymes, the oxygation treatments slightly improved the activities of $\alpha$-1,4-glucosidase (Fig. 4c), $\beta$-1,4-xylosidase (Fig. 4d), and phenol oxidase (Fig. 4f) compared

between them (Fig. 4e).
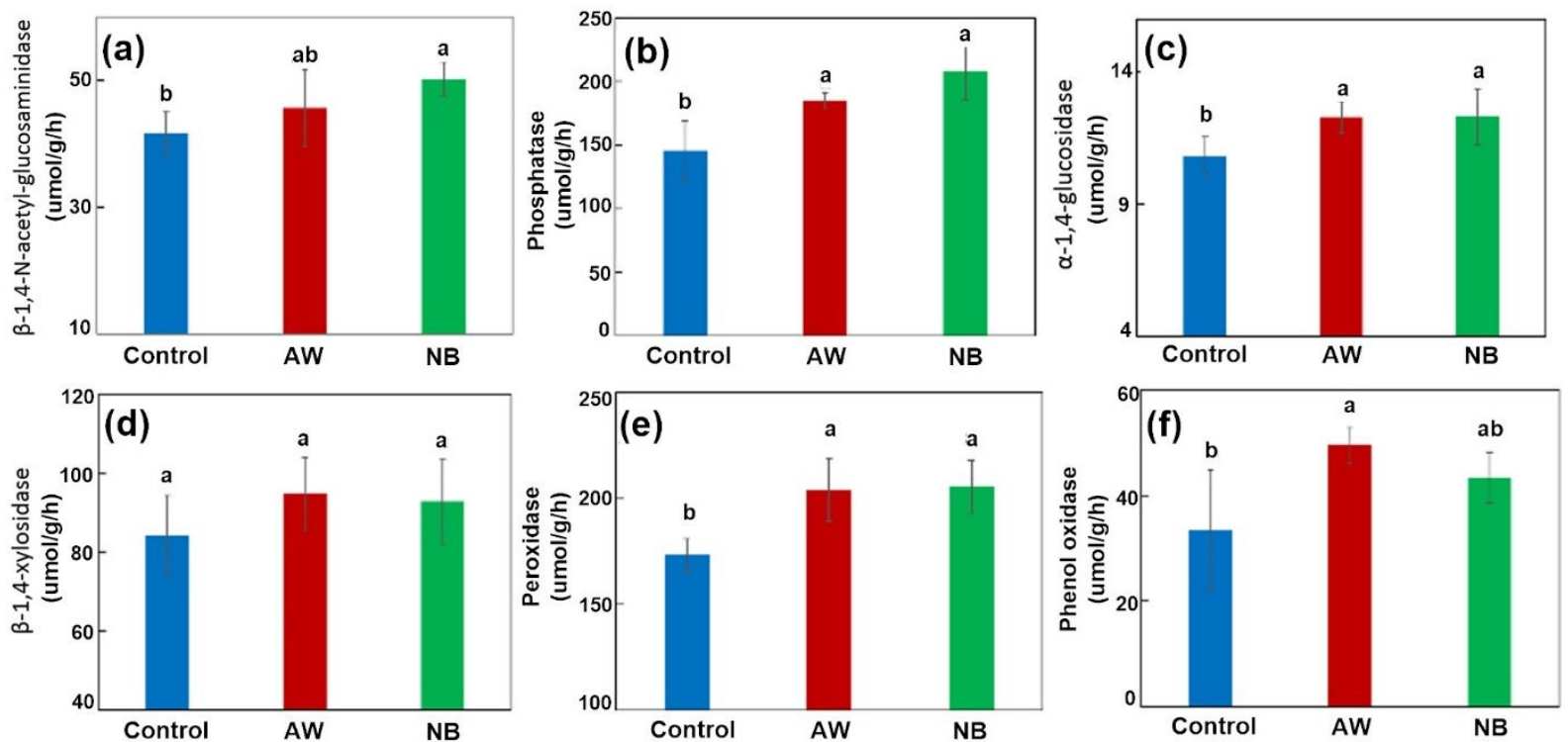

Fig. 4. Effect of oxygation on soil enzyme activities: (a) $\beta-1,4-N$-acetyl-glucosaminidase, (b)

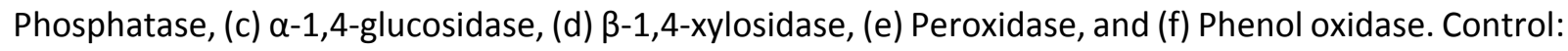




\subsection{Response of microbial metabolic functions}

The community-level physiological profiling was assessed to evaluate the response of

(NB) irrigation groups. treatment groups.

\section{Table 1}

the microbial metabolic functions to the NB irrigation. The soil microbial diversity and activity were reflected in the Shannon diversity index and the AWCD values, respectively. Both of these were significantly higher in the oxygation treatment groups compared to the control group (Table 1). The levels of microbial diversity and activity were similar between NB and AW

The microbial metabolic functional diversity and average well colour development (AWCD) level from the Biolog EcoPlate ${ }^{\mathrm{TM}}$ analysis in control, pump-aerated water (AW) and nanobubble-aerated water

\begin{tabular}{lll}
\hline Group & Shannon diversity $\left(\mathrm{H}^{\prime}\right)$ & AWCD $(590 \mathrm{~nm})$ \\
\hline Control & $3.344 \pm 0.003^{\mathrm{b}}$ & $2.0 \pm 0.1^{\mathrm{b}}$ \\
AW & $3.387 \pm 0.001^{\mathrm{a}}$ & $2.4 \pm 0.1^{\mathrm{a}}$ \\
NB & $3.388 \pm 0.005^{\mathrm{a}}$ & $2.5 \pm 0.1^{\mathrm{a}}$ \\
\hline
\end{tabular}

272 Different superscript letters beside the number indicate a significant difference at $P<0.05$.

274 into six groups (guilds), miscellaneous, carbohydrates, polymers, carboxylic acids, amino acids

275 and amines/amides, in order to reduce the complexity of the data obtained. Overall, the 276 capabilities of the soil microbial communities for carbon utilization were strengthened in the 277 oxygation treatment groups (Fig. 5a). However, only amino acids showed significantly higher 
278 utilization in AW and NB treatment groups than in the control group. Further evaluation was used to transform the multivariate vectors into two uncorrelated principal component vectors 280 (Fig. 5b). The two-dimensional PCA of the community-level of physiological profiles explained $68.6 \%$ of the total variance, with the first principle component having a greater power of separation (42.7\%). The data from the oxygation treatment groups located in the upper right section of the figure, were significantly different from the control group, shown on the left of the plot. The analysis of the loading of carbon sources on PC1 showed that AW and NB treatments were indeed factors that influenced the catabolic diversity of microbial

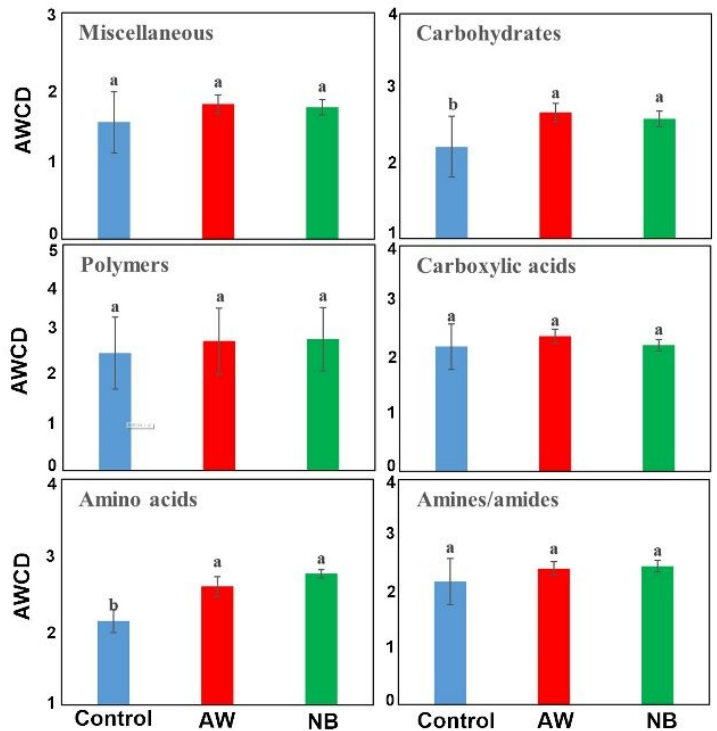

(a)

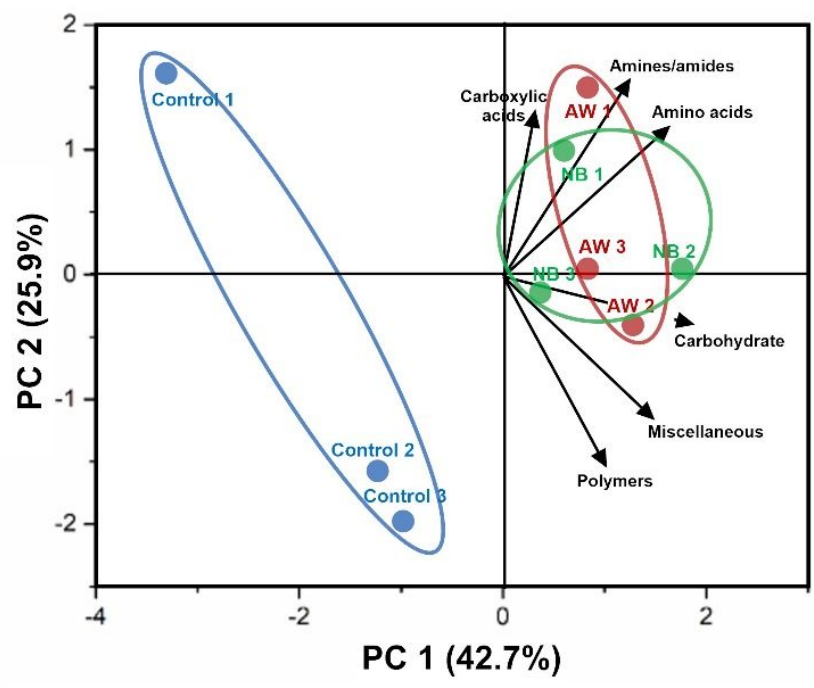

(b)

Fig. 5. Microbial community carbon source utilization levels (a) and the principal component analysis (PCA) ordination of the carbon source utilization patterns (b) from Biolog Ecoplates incubated for 168 


\subsection{Tomato growth and yield}

The soil oxygation treatments from both AW and NB significantly improved the tomato

growth as measured by improved stem diameter (Fig. 6a) and plant height (Fig. 6b) at the early

stage of plant growth on day 15 and 30 . However, by day 45 , these differences were not

b). The tomato biomass from the NB oxygation group yielded a significantly higher value

(around $547 \mathrm{~g} /$ plant) than that (around $447 \mathrm{~g} /$ plant) from the control group, an enhancement

around $523 \mathrm{~g} /$ plant, which was $17 \%$ higher than the control group.
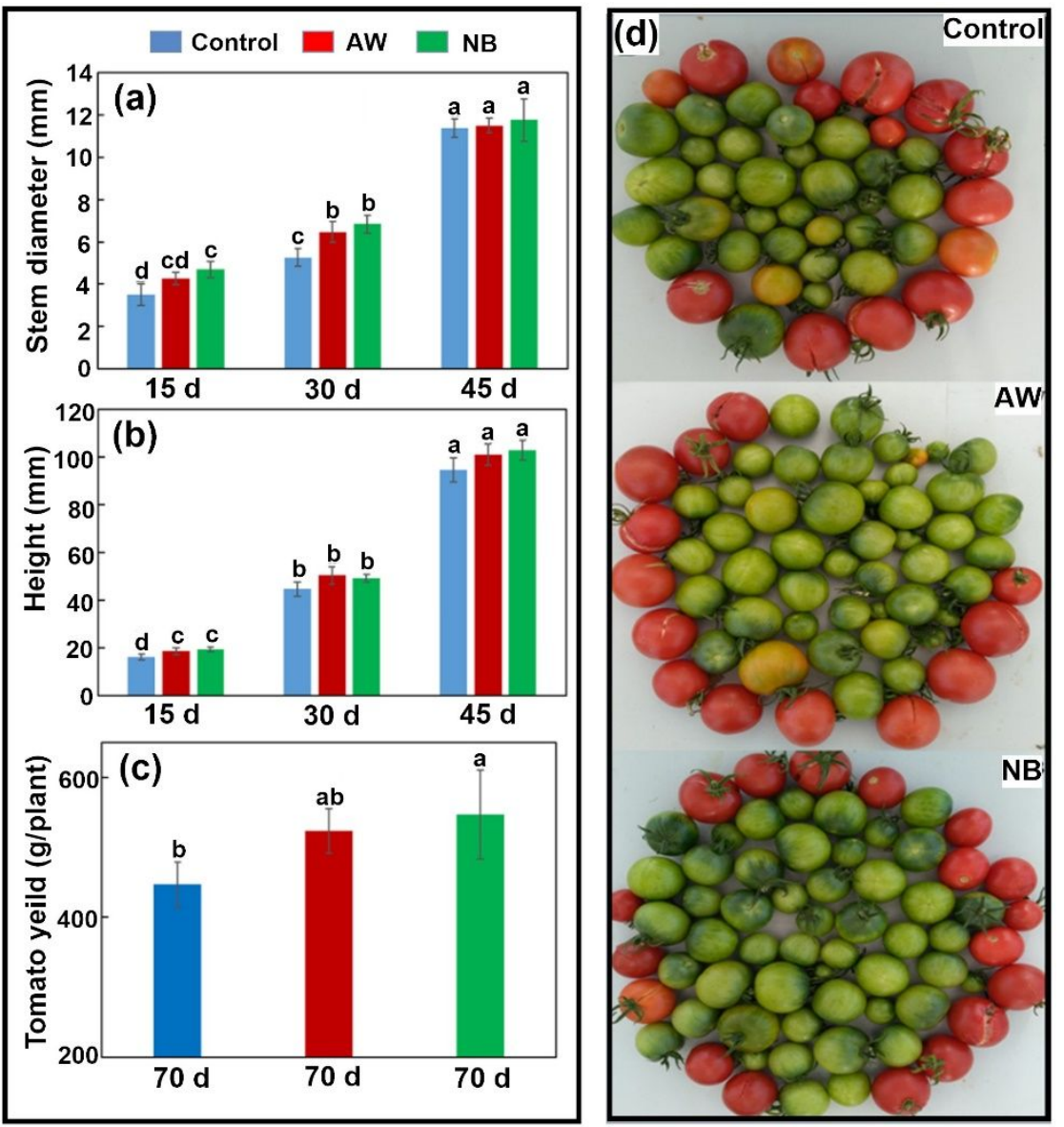

Fig. 6. Tomato plant growth, i.e. (a) stem dimension and (b) plant height, and (c, d) tomato biomass

yield at the end of the soil column experiment. Control: irrigation with original water, AW: irrigation 
with pump aerated water, NB: irrigation with nanobubble aerated water. Different letters above the bars in each figure indicate significant difference between the values $(P<0.05)$.

\section{Discussion}

In the process of agricultural production, fertilization and irrigation are key practices for improving the yield of crops. ${ }^{32}$ To reduce environmental issues caused by overuse of chemical fertilizers without influencing crop yield, organic fertilizer has been recommended as a partial, or even complete, substitute. ${ }^{33}$ Oxygation (aerated irrigation) is an irrigation technology which is well recognized to enhance crop yield by improving the aerobic environment of the root zone and to increase root uptake of water and nutrients. ${ }^{34}$ However, the study focused on the effect of both soil oxygation and organic fertilizer application on crop growth is still limited. In the present study, two oxygation methods, irrigation by traditional pump-aerated water and nanobubble-aerated water, were applied in growth of tomatoes with organic fertilizer.

The majority of the nutrients, stored in organic form in organic fertilizers, cannot be directly utilized by the crops. The release of plant-available nutrients, such as $\mathrm{N}$ and $\mathrm{P}$, from organic matter involves biological decomposition processes, which are highly dependent on the oxygen content and moisture level in the soil. Oxygation offers soil sufficient water and oxygen at the same time, thus the plant-available $\mathrm{N}$ and $\mathrm{P}$ content can be increased, such as occurs under ventilation treatment. ${ }^{35}$ It supports the present finding that the irrigation of both normal pump-aerated and nanobubble-aerated waters significantly increased the release of plant-available $\mathrm{N}$ and $\mathrm{P}$ from organic fertilizer (Fig. 3). Specifically, nitrogen content organic 325 fertilizer can release $\mathrm{NH}_{4}^{+}$through the biodegradation process under the aerobic condition. If 
the oxygation approach substantially supply the oxygen, $\mathrm{NH}_{4}{ }^{+}$can be transformed to plant available $\mathrm{NO}_{3}{ }^{-}$through nitrification process. ${ }^{36}$ Thus, the substantially higher content of $\mathrm{NO}_{3}{ }^{-}$ compared with $\mathrm{NH}_{4}{ }^{+}$(Fig. 3a), may be due to the dominant nitrification process under such an aerobic environment. Moreover, the significantly higher nutrients under NB oxygation may be attributable to the large amounts of nanoscale bubbles in NB-aerated irrigation water (Fig. 2). The NB has a low buoyancy and long lifetime, where the filled air or oxygen can be slowly dissolved into the soil interstitial water and sustainably supply the oxygen ${ }^{37}$ required for the mineralization of organic fertilizer. The effective oxygen supply by NBs may also result the high speed of the organic fertilizer mineralization and plant-available $\mathrm{N}$ in the soil achieved the highest value in day 17 (Fig. 3a). Similar level was shown in day 28 may cause by the thoroughly plant-available $\mathrm{N}$ release under the oxygation treatment. It is differentiated from the normal pump-aerated water, where the oversaturated oxygen can escape from the irrigation water quickly to the atmosphere resulting in a comparatively reduced oxygenation effect and speed on the rhizosphere environment.

Agriculture practices, such as irrigation, can influence soil microenvironment and result in the shift of soil microorganisms. ${ }^{38}$ Higher soil aeration was reported to stimulate microbial biomass and change community composition in paddy fields, ${ }^{39}$ findings which support the determination of improved microbial biomass, activity and diversity in the aerated irrigation groups in this study (Fig. 3d and Table 1). The differences of microbial metabolic functions in the soil samples were indicated by the utilization of 31 kinds of carbon sources during the Biolog microplate analysis. ${ }^{40,41}$ The clearly differentiated metabolic function groups between the aerated irrigation group and the control (Fig. 5), further demonstrated that the 
oxygenation treatments not only boosted microbial activity, but also played a constructive role in increasing functional diversity of soil microbial communities. ${ }^{42}$ Even though the microbial metabolic functions (Fig. 5b) were undifferentiated between the normal pumpaerated and nanobubble-aerated irrigation treatments, gene level differences in the soil microbial communities may be significant, which need to be further studied. Changes in metabolic function and diversity of soil microbial community might cause the fluctuation of soil enzyme activities. Previous studies found some soil enzyme activities were greater in soils treated by aeration than in those without. ${ }^{35,44}$ In this study, we found soil enzyme activities were increased by oxygation treatment. The mechanism may be due to the stimulation of microbial growth and the increase in the activity of the extracellular enzymeorgano complex. ${ }^{45}$ Among the 6 enzymes we measured (Fig. 4), the activities of C-cycling enzymes ( $\alpha$-1,4-glucosidase, $\beta$-1,4-xylosidase, phenol oxidase and peroxidase), a $\mathrm{N}$-cycling enzyme ( $\beta$-1,4-N-acetyl-glucosaminidase) and a P-cycling enzyme (Phosphatase) suggest a shift toward increased $\mathrm{C}$ acquisition as $\mathrm{N}$ and $\mathrm{P}$ becomes readily available for plant growth. Increases in enzyme activities may reflect and stimulate soil microbial activity, thereby increasing the quantities of nutrients available to plants. ${ }^{46}$ However, the similar enzymes activities were observed in the two oxygation treatments, which may due to the relative short soil incubation time before the sampling. plant growth (15, 30 days) in both oxygation treatments (Fig. 6). The result is consistent with 
previous studies showing that oxygation treatment can improve the rate of organic fertilizer

370

371

372

373

374

375

376

377

378

379

380

381

382

383

384

385

386

387

388

mineralization and result in a fast crop growth. ${ }^{47}$ However, the plant growth (stem diameter and height) achieved the same level at the final stage after the fruit had ripened (Fig. 6). Similar results were also found for the tomato cultivation under aerated irrigation. ${ }^{12}$ which may due to the same amount of fertilizer application in all groups. It has been reported that the tomato yield with oxygation treatment was around $19 \%$ higher when compared to non-oxygation treatment. ${ }^{48}$ In the present study, the AW treatment with traditional pump-aerated irrigation reached a similar increase $(17 \%)$ of tomato production, while the nanobubble-aerated irrigation achieved around a $23 \%$ improvement in yield (Fig. 6 c), which is comparable to the losses (up to $25 \%$ ) generally attributed to the transition from traditional farming using chemical fertilizer to organic farming using organic fertilizer. ${ }^{9}$ Therefore, the present study provides a promising eco-friendly agri-nanotechnology, with which to increase crop production in organic farming. Nevertheless, further study should be conducted to evaluate the effect of NB oxygation on organic fertiliser mineralization and crop growth directly in the soil column experiment before the application. Notably, in the present study, the plantavailable nutrients and microbial communities from the nanobubble irrigation treatment are only slightly different to those obtained by conventional pump-aerated irrigation group. The relatively larger tomato yield may also be due to the synergistic functions of improvement in organic fertilizer mineralization and plant physiology modification by the nanobubbles. ${ }^{18,} 19$ Thus, the plant gene alteration and fruit nutrition changes will need to be further studied.

In conclusion, the nanobubble oxygation treatment for organic farming was evaluated for the improvement of organic fertilizer mineralization and tomato production, compared 
with the traditional pump-aerated oxygation technique and with un-oxygenated control 392 groups. Levels of plant-available $\mathrm{N}$ and $\mathrm{P}$ were substantially improved, associated with the stimulation of soil enzymatic activity due to the oxygation treatment. Moreover, this 394 treatment, in an organic farming context, significantly enhanced the soil microbial biomass, activity, diversity, and metabolic functionality. Even through the differences between the nanobubble oxygation and tradition pump-aerated oxygation treatments were not always significant, final tomato yields improved by approximately $23 \%$, while the pump-aerated oxygenation treatment gave an improvement in crop yield of $17 \%$, when compared to the control group. The results indicated that the proposed agri-nanotechnology, nanobubble oxygation, is a potentially promising approach to stimulate mineralization of organic fertilizer and thus improve crop growth, during a transition from using chemical fertilizer to organic fertilizer for organic farming.

403

404

\section{Acknowledgments}

This work was funded by the Ministry of Science and Technology 973 project (No. 2015 CB150500), China Postdoctoral Science Foundation (2017M621672), National Natural Science Foundation of China (41701339) and Medical Technologies and Advanced Materials Strategic Theme at Nottingham Trent University. We thank Mick Cooper for proof reading.

\section{References}

(1) Zhu, Z.; Chen, D. Nitrogen fertilizer use in China-Contributions to food production, impacts on the environment and best management strategies. Nutr. Cycl. Agroecosys. 2002, 63, (2-3), 117-127.

(2) Serio, F.; Miglietta, P. P.; Lamastra, L.; Ficocelli, S.; Intini, F.; De Leo, F.; De Donno, A. Groundwater 
412

413

414

415

416

417

418

nitrate contamination and agricultural land use: A grey water footprint perspective in Southern Apulia Region (Italy). Sci. Total Environ. 2018, 645, 1425-1431.

(3) Zhang, H.; Shang, Y.; Lyu, T.; Chen, J.; Pan, G. Switching Harmful Algal Blooms to Submerged Macrophytes in Shallow Waters Using Geo-engineering Methods: Evidence from a 15N Tracing Study. Environ. Sci. Technol. 2018, 52, (20), 11778-11785.

(4) Pan, G.; Lyu, T.; Mortimer, R. Comment: Closing phosphorus cycle from natural waters: recapturing phosphorus through an integrated water-energy-food strategy. J. Environ. Sci. 2018, 65, 375376.

(5) Smith, L.; Siciliano, G. A comprehensive review of constraints to improved management of fertilizers in China and mitigation of diffuse water pollution from agriculture. Agr. Ecosyst. Environ. 2015, 209, 15-25.

(6) Reganold, J. P.; Wachter, J. M. Organic agriculture in the twenty-first century. Nat. Plants 2016, 2, (2), 15221.

(7) Rahmann, G.; Ardakani, M. R.; Bàrberi, P.; Boehm, H.; Canali, S.; Chander, M.; David, W.; Dengel, L.; Erisman, J. W.; Galvis-Martinez, A. C. Organic Agriculture 3.0 is innovation with research. Organic Agri. 2017, 7, (3), 169-197.

(8) Agehara, S.; Warncke, D. Soil moisture and temperature effects on nitrogen release from organic nitrogen sources. Soil Sci. Soc. Am. J. 2005, 69, (6), 1844-1855.

(9) Forster, D.; Andres, C.; Verma, R.; Zundel, C.; Messmer, M. M.; Mäder, P. Yield and economic performance of organic and conventional cotton-based farming systems-results from a field trial in India. PLoS One 2013, 8, (12), e81039.

(10) Seufert, V.; Ramankutty, N.; Foley, J. A. Comparing the yields of organic and conventional 
434

435

436

agriculture. Nature 2012, 485, (7397), 229.

(11) Sang, H.; Jiao, X.; Wang, S.; Guo, W.; Salahou, M. K.; Liu, K. Effects of micro-nano bubble aerated irrigation and nitrogen fertilizer level on tillering, nitrogen uptake and utilization of early rice. Plant, Soil Environ. 2018, 64, (7), 297-302.

(12) Li, Y.; Niu, W. Q.; Dyck, M.; Wang, J. W.; Zou, X. Y. Yields and Nutritional of Greenhouse Tomato in Response to Different Soil Aeration Volume at two depths of Subsurface drip irrigation. Sci. Rep. 2016, 6 .

(13) Şimşek, M.; Tonkaz, T.; Kaçıra, M.; Çömlekçioğlu, N.; Doğan, Z. The effects of different irrigation regimes on cucumber (Cucumbis sativus L.) yield and yield characteristics under open field conditions. Agric. Water Manag. 2005, 73, (3), 173-191.

(14) Pan, G.; He, G.; Zhang, M.; Zhou, Q.; Tyliszczak, T.; Tai, R.; Guo, J.; Bi, L.; Wang, L.; Zhang, H. Nanobubbles at Hydrophilic Particle-Water Interfaces. Langmuir 2016, 32, (43), 11133-11137.

(15) Lyu, T.; Wu, S.; Mortimer, R. J.; Pan, G. Nanobubble Technology in Environmental Engineering: Revolutionization Potential and Challenges. Environ. Sci. Technol. 2019, 53, (13), 7175-7176.

(16) Wang, L.; Miao, X.; Lyu, T.; Pan, G. Quantification of Oxygen Nanobubbles in Particulate Matters and Potential Applications in Remediation of Anaerobic Environment. ACS Omega 2018, 3, (9), 1062410630.

(17) Liu, Y.; Zhou, Y.; Wang, T.; Pan, J.; Zhou, B.; Muhammad, T.; Zhou, C.; Li, Y. Micro-nano bubble water oxygation: Synergistically improving irrigation water use efficiency, crop yield and quality. J. Clean. Prod. 2019, 222, 835-843.

(18) Ebina, K.; Shi, K.; Hirao, M.; Hashimoto, J.; Kawato, Y.; Kaneshiro, S.; Morimoto, T.; Koizumi, K.; Yoshikawa, H. Oxygen and air nanobubble water solution promote the growth of plants, fishes, and 
456

457

458

459

460

461

462

463

464

465

466

467

468

469

470

471

472

473

474

475

476

477

mice. PLoS One 2013, 8, (6), e65339.

(19) Ahmed, A. K. A.; Shi, X.; Hua, L.; Manzueta, L.; Qing, W.; Marhaba, T.; Zhang, W. Influences of air, oxygen, nitrogen, and carbon dioxide nanobubbles on seed germination and plant growth. J. Agri. Food Chem. 2018, 66, (20), 5117-5124.

(20) Chen, X.; Dhungel, J.; Bhattarai, S. P.; Torabi, M.; Pendergast, L.; Midmore, D. J. Impact of oxygation on soil respiration, yield and water use efficiency of three crop species. J. Plant Ecol. 2010, 4, (4), 236-248.

(21) Noll, M.; Matthies, D.; Frenzel, P.; Derakshani, M.; Liesack, W. Succession of bacterial community structure and diversity in a paddy soil oxygen gradient. Environ. Microbiol. 2005, 7, (3), 382-395.

(22) Burns, R. G.; DeForest, J. L.; Marxsen, J.; Sinsabaugh, R. L.; Stromberger, M. E.; Wallenstein, M. D.; Weintraub, M. N.; Zoppini, A. Soil enzymes in a changing environment: current knowledge and future directions. Soil Biol. Biochem. 2013, 58, 216-234.

(23) Tu, C.; Ristaino, J. B.; Hu, S. Soil microbial biomass and activity in organic tomato farming systems: Effects of organic inputs and straw mulching. Soil Biol. Biochem. 2006, 38, (2), 247-255.

(24) Shen, D.; Ye, C.; Hu, Z.; Chen, X.; Guo, H.; Li, J.; Du, G.; Adl, S.; Liu, M. Increased chemical stability but decreased physical protection of soil organic carbon in response to nutrient amendment in a Tibetan alpine meadow. Soil Biol. Biochem. 2018, 126, 11-21.

(25) Jian, S.; Li, J.; Chen, J.; Wang, G.; Mayes, M. A.; Dzantor, K. E.; Hui, D.; Luo, Y. Soil extracellular enzyme activities, soil carbon and nitrogen storage under nitrogen fertilization: A meta-analysis. Soil Biol. Biochem. 2016, 101, 32-43.

(26) Luo, L.; Gu, J.-D. Nutrient limitation status in a subtropical mangrove ecosystem revealed by analysis of enzymatic stoichiometry and microbial abundance for sediment carbon cycling. Int. 
478

479

480

481

482

483

484

485

486

487

488

489

490

491

492

493

494

495

496

497

498

499

Biodeter. Biodegr. 2018, 128, 3-10.

(27) Hendriksen, N.; Creamer, R.; Stone, D.; Winding, A. Soil exo-enzyme activities across EuropeThe influence of climate, land-use and soil properties. Appl. Soil Ecol. 2016, 97, 44-48.

(28) Zhao, S.; Li, K.; Zhou, W.; Qiu, S.; Huang, S.; He, P. Changes in soil microbial community, enzyme activities and organic matter fractions under long-term straw return in north-central China. Agr. Ecosyst. Environ. 2016, 216, 82-88.

(29) Zhang, L.; Lyu, T.; Zhang, Y.; Button, M.; Arias, C. A.; Weber, K. P.; Brix, H.; Carvalho, P. N. Impacts of design configuration and plants on the functionality of the microbial community of mesocosm-scale constructed wetlands treating ibuprofen. Water Res. 2018, 131, 228-238.

(30) Lv, T.; Carvalho, P. N.; Zhang, L.; Zhang, Y.; Button, M.; Arias, C. A.; Weber, K. P.; Brix, H. Functionality of microbial communities in constructed wetlands used for pesticide remediation: Influence of system design and sampling strategy. Water Res. 2017, 110, 241-251.

(31) Zhang, Y.; Lyu, T.; Zhang, L.; Button, M.; Arias, C. A.; Weber, K. P.; Shi, J.; Chen, Z.; Brix, H.; Carvalho, P. N. Microbial community metabolic profiles in saturated constructed wetlands treating iohexol and ibuprofen. Sci. Total Environ. 2019, 651, 1926-1934.

(32) Wang, X. K.; Xing, Y. Y. Evaluation of the effects of irrigation and fertilization on tomato fruit yield and quality: a principal component analysis. Sci. Rep. 2017, 7.

(33) Rigby, D.; Cáceres, D. Organic farming and the sustainability of agricultural systems. Agri. Syst. 2001, 68, (1), 21-40.

(34) Du, Y.-D.; Niu, W.-Q.; Gu, X.-B.; Zhang, Q.; Cui, B.-J.; Zhao, Y. Crop yield and water use efficiency under aerated irrigation: A meta-analysis. Agri. Water Manag. 2018, 210, 158-164.

(35) Xiao, Y.; Peng, F.; Dang, Z.; Jiang, X.; Zhang, J.; Zhang, Y.; Shu, H. Influence of rhizosphere 
500

501

502

503

504

505

506

507

508

509

510

511

512

513

514

515

516

517

518

519

520

521

ventilation on soil nutrient status, root architecture and the growth of young peach trees. Soil Sci. Plant

Nutr. 2015, 61, (5), 775-787.

(36) Lyu, T.; He, K.; Dong, R.; Wu, S. The intensified constructed wetlands are promising for treatment of ammonia stripped effluent: nitrogen transformations and removal pathways. Environ. Pollut. 2018, $236,273-282$

(37) Zhang, H.; Lyu, T.; Bi, L.; Tempero, G.; Hamilton, D. P.; Pan, G. Combating hypoxia/anoxia at sediment-water interfaces: A preliminary study of oxygen nanobubble modified clay materials. Sci. Total Environ. 2018, 637, 550-560.

(38) Xiao, D.; Xiao, S.; Ye, Y.; Zhang, W.; He, X.; Wang, K. Microbial biomass, metabolic functional diversity, and activity are affected differently by tillage disturbance and maize planting in a typical karst calcareous soil. J. Soil. Sediment 2018, 1-13.

(39) Yuan, Y.; Dai, X.; Xu, M.; Wang, H.; Fu, X.; Yang, F. Responses of microbial community structure to land-use conversion and fertilization in southern China. Eur. J. Soil Biol. 2015, 70, 1-6.

(40) Manjunath, M.; Kumar, U.; Yadava, R. B.; Rai, A. B.; Singh, B. Influence of organic and inorganic sources of nutrients on the functional diversity of microbial communities in the vegetable cropping system of the Indo-Gangetic plains. C. R. Biol. 2018, 341, (6), 349-357.

(41) Kumar, U.; Shahid, M.; Tripathi, R.; Mohanty, S.; Kumar, A.; Bhattacharyya, P.; Lal, B.; Gautam, P.; Raja, R.; Panda, B. B.; Jambhulkar, N. N.; Shukla, A. K.; Nayak, A. K. Variation of functional diversity of soil microbial community in sub-humid tropical rice-rice cropping system under long-term organic and inorganic fertilization. Ecol. Indic. 2017, 73, 536-543.

(42) Sun, Y.; Yang, Z.; Zhao, J.; Li, Q. Functional diversity of microbial communities in sludge-amended soils. Phys. Procedia 2012, 33, 726-731. 
(43) Zornoza, R.; Guerrero, C.; Mataix-Solera, J.; Arcenegui, V.; García-Orenes, F.; Mataix-Beneyto, J.

523

524

525

526

527

528

529

530

531

532

533

534

535

536

537

Assessing air-drying and rewetting pre-treatment effect on some soil enzyme activities under

Mediterranean conditions. Soil Biol. Biochem. 2006, 38, (8), 2125-2134.

(44) Li, Y.; Niu, W. Q.; Wang, J. W.; Liu, L.; Zhang, M. Z.; Xu, J. Effects of Artificial Soil Aeration Volume and Frequency on Soil Enzyme Activity and Microbial Abundance when Cultivating Greenhouse Tomato. Soil Sci. Soc. Am. J. 2016, 80, (5), 1208-1221.

(45) Ouyang, Y.; Reeve, J. R.; Norton, J. M. Soil enzyme activities and abundance of microbial functional genes involved in nitrogen transformations in an organic farming system. Biol. Fert. Soils 2018, 54, (4), 437-450.

(46) Monkiedje, A.; Ilori, M. O.; Spiteller, M. Soil quality changes resulting from the application of the fungicides mefenoxam and metalaxyl to a sandy loam soil. Soil Biol. Biochem. 2002, 34, (12), 19391948.

(47) Li, Y.; Jia, Z.-x.; Niu, W.-Q.; Wang, J.-w. Impact of post-infiltration soil aeration at different growth stages of sub-surface trickle-irrigated tomato plants. Int. Agrophys. 2016, 30, (3), 331-337.

(48) Bhattarai, S. P.; Pendergast, L.; Midmore, D. J. Root aeration improves yield and water use efficiency of tomato in heavy clay and saline soils. Sci. Hort. 2006, 108, (3), 278-288. 